TITLE:

\title{
Affinity between Juvenile Tantulocarida Thoracopods and Postantennular Appendages of Maxillopodan Nauplii (Crustacea)
}

AUTHOR(S):

Ito, Tatsunori

CITATION:

Ito, Tatsunori. Affinity between Juvenile Tantulocarida Thoracopods and Postantennular Appendages of Maxillopodan Nauplii (Crustacea). PUBLICATIONS OF THE SETO MARINE BIOLOGICAL LABORATORY 1985, 30(1-3): 151-166

ISSUE DATE:

1985-06-30

URL:

http://hdl.handle.net/2433/176096

RIGHT: 


\title{
Affinity between Juvenile Tantulocarida Thoracopods and Postantennular Appendages of Maxillopodan Nauplii (Crustacea)
}

\author{
By
}

\section{Tatsunori Itô}

Seto Marine Biological Laboratory, Kyoto University, Shirahama,

Wakayama, 649-22, Japan

With Text-figures $1-3$

\begin{abstract}
Thoracopods of juvenile Tantulocarida (Crustacea) show a great deal of similarity with the postantennular appendages, especially the mandible, of some maxillopodan nauplii such as copepods, cirripeds, and Hansen's y larvae. The phylogenetic implication of this similarity is discussed within the context of the possible origin of tantulocarid thoracopods.
\end{abstract}

The class Tantulocarida was erected by Boxshall \& Lincoln (1983) to accommodate four species of ectoparasitic crustaceans: Basipodella harpacticola Becker, 1975, B. atlantica Boxshall et Lincoln, 1983, Deoterthron dentatum Bradford et Hewitt, 1980 , and $D$. aselloticola Boxshall et Lincoln, 1983. Later on, a fifth member of the class, D. megacephala Lincoln et Boxshall, 1983, was added and a sound definition of the class seems to have been reached. However, the systematic position of this group of the Crustacea is still debatable. The first species, $B$. harpacticola, was reported as a copepod by Becker (1975), but Bradford \& Hewitt (1980) asserted that Basipodella and their new genus Deoterthron were "cirripeds with characters in common with both Rhizocephala and Ascothoracica," and so placed them within the Maxillopoda. Bradford \& Hewitt's opinion, however, was rejected by Boxshall \& Lincoln (1983) who erected for these crustaceans a new taxon called Tantulocarida and treated it at the same rank with the Copepoda and Cirripedia. Certain thoracopods of $B$. harpacticola and $D$. aselloticola bear an endite with a seta on the protopodite; this nature was considered by Boxshall \& Lincoln (1983, p. 15) as a major feature to distinguish the tantulocarids from "all other groups at the maxillopodan level of organization." Their argument is apparently based upon a view point that "all other groups at the maxillopodan level of organization" are devoid of thoracopodal endite (see also Hessler, 1982, p. 163, for the absence of the endite in the Maxillopoda). As pointed out by them, it is true that the thoracopods of tantulocarids clearly differ from the thoracic appendages of adult and juvenile maxillopodans, especially in respect of the endite. However, it is also true that certain structure which resembles the endite of the tantulocarid thoracopods does exist on the postantennular appendages of some (but not all) nauplius larvae of crustaceans "at the

Publ. Seto Mar. Biol. Lab., 30 (1/3), 151-166, 1985.

(Article 7) 
maxillopodan level of organization." Moreover, the peculiar endopodite on the tantulocarid thoracopods may be indeed related to the endopodite of postantennular appendages found in some maxillopodan nauplii. Be that as it may, I shall demonstrate in the following some general similarity in the basic morphology, which have so far been overlooked or underestimated, between the tantulocarid thoracopods and certain postantennular appendages of nauplius (including metanauplius) larvae of some maxillopodans (hence, malacostracans and most of non-maxillopodan taxa are excluded from the following discussion). I shall also entertain another possible interpretation on the phylogenetic significance of this peculiar tantulocarid thoracopods.

Before entering the main subject, it is necessary to comment on the usage of the term 'maxillopodan' because the taxonomic validity of the Maxillopoda Dahl itself is still a matter of debate (see F.R. Schram, 1982, Hessler, 1982, Boxshall, 1983, Grygier, 1983). In the present paper, I do not intend to discuss the validity of the Maxillopoda as a taxon, and the term is used throughout the section 1 for the convenience of referring to an informal group including copepods, cirripeds in the strict sence (excluding ascothoracids) and the crustaceans known as Hansen's y larvae (nauplius y and cypris y, see T.A. Schram, 1970a, b, 1972; genus name will be given in Itô, in press). Although ascothoracids, which were separated from the Cirripedia and placed under a formal taxon Ascothoracida by Wagin (1947) and that was asserted by Grygier (1983, 1984b) to form a stem group of the Maxillopoda, they are purposely omitted from the following discussion because their endite-less naupliar appendages are of little value for discussion in the section 1, though an exceptional case is known for the nauplius of Baccalaureus japonicus Broch reported by Yosii (1931). The Branchiura, in spite of its inclusion in Dahl's Maxillopoda, is also disregarded in the section 1 because their larvae are not comparable to the nauplius or metanauplius of other maxillopodans. Mystacocarids, which are "the weakest component of the Maxillopoda" (Boxshall \& Lincoln, 1983, p. 14), also are disregarded in the section 1, since their naupliar antenna and mandible have much developed rami than those of other maxillopodan nauplii, though certain relations are seen between them (see Delamare Deboutteville, 1953). Recently, Grygier (1984b: unpublished thesis) proposed a new classificatory system of the Maxillopoda including Hansen's y larvae. Although I agree in his system of maxillopodan classification, I do not adopt it here for the sake of avoiding confusion about the date if and when his thesis is published.

\section{Tantulocarid Thoracopods and Naupliar Appendages of Maxillopoda}

\section{1-1. Thoracopods of Juvenile Tantulocarida.}

All known tantulocarid adults show a strong degenerative development owing to their parasitic mode of life, and their thoracopods are not exemplified, though an endite persists on each of their thoracopods except for the last pair. Contrary to the adult, juvenile tantulocarids, even though they are parasitic, have somewhat 

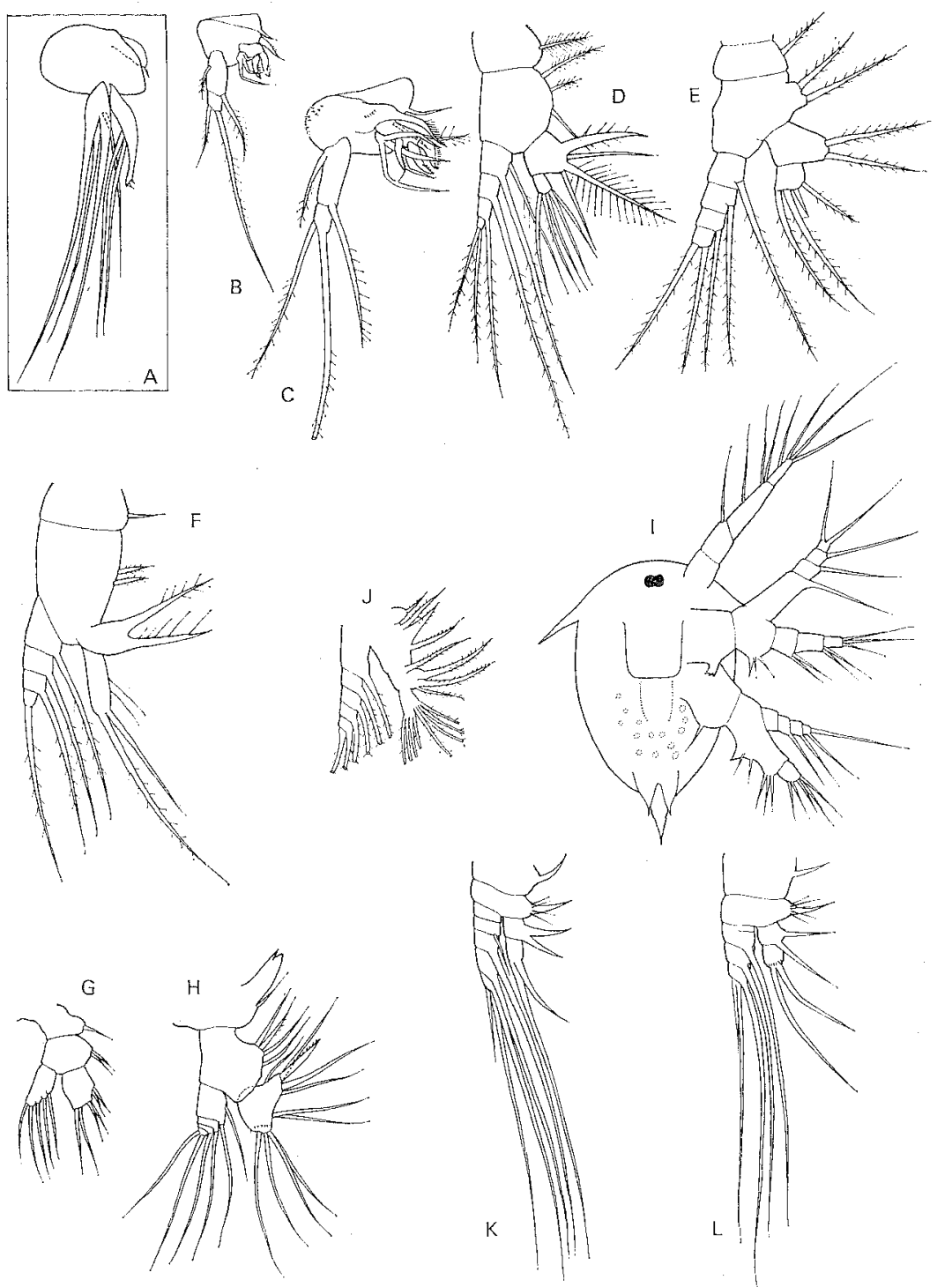

Fig. 1. Comparison of a tantulocarid thoracopod and naupliar appendages of some maxillopodans. A. Second thoracopod of a juvenile of the tantulocarid Deoterthron aselloticola (after Boxshall \& Lincoln, 1983); B, C. Mandible of NI and NVI of the harpacticoid copepod Canthocamptus mirabilis (after Itô \& Takashio, 1980); D. Mandible of NI of the harpacticoid copepod Longipedia coronata (after Nicholls, 1935); E. Mandible of NI of the harpacticoid copepod Canuella perplexa (after Vincx \& Heip, 1979, modified); F. Mandible of NI of the cyclopoid copepod Oithona brevicomis (after Uchima, 1979, modified); G, H. Mandible of NI and NVI of the calanoid copepod Centropages typicus (after Lawson \& Grice, 1970); I. NI of the cirriped Balanus amphitrite hawaiiensis (after Hudinaga \& Kasahara, 1942, modified); J. Mandible of NV of the cirriped Balanus eburneus (after Costlow \& Bookhout, 1957, modified); K, L. Second antenna and mandible of Hansen's nauplius y (after Schram, 1972, modified). 
less modified thoracopods, hence, they are taken on for comparison. The second thoracopod of a juvenile $D$. aselloticola illustrated in Fig. $1-A$ is used to represent the tantulocarid thoracopods 1-5 (thoracopod 6 is rudimentary).

Lincoln \& Boxshall (1983) reported a spoon-shaped spine, instead of two spinules, on each endopodite of thoracopods 2-5 of $D$. dentatum and $D$. megacephala. This means that the two apical spines on the endopodite illustrated in Fig. 1-A may be considered as the chitinous rims of such a spoon-shaped spine. The structure of the juvenile thoracopods 1-5 seems to be less variable when other species are taken into consideration. Some notable deviations from the representative thoracopod illustrated in Fig. 1-A are as follows: the endopodite of thoracopod 1 has only one seta (in D. megacephala) or no seta (in D. aselloticola) and the exopodite of thoracopod 1 (in $D$. dentatum) has only two setae.

\section{1-2. Endite.}

The endite of tantulocarid thoracopods is represented by a simple process arising from the proximal inner edge of the protopodite and bearing a short apical seta. Next, I shall enumerate the similar structure found in some maxillopodan naupliar appendages.

Fig. 1-B shows the mandible of the nauplius I (the first nauplius) of Canthocamptus mirabilis Š Šrba (Copepoda, Harpacticoida) reported by Itô \& Takashio (1980). Although this species is not primitive among harpacticoids, its naupliar mandible bears the elements that are comparable with the tantulocarid thoracopods. This naupliar mandible consists of two-segmented protopodite (sympodite), exopodite, and endopodite. As it can be seen in the figure, a seta arises from the inner edge of the short proximal segment of the protopodite. (Since the identity of this segment - precoxa or coxa- is a matter of dispute (cf. Lang, 1965, p. 10, Rosenfield, 1967, p. 22), I call it simply 'proximal segment' in the present paper.) At later naupliar stages of this harpacticoid, the proximal segment becomes protruded inwards (Fig. 1-C). I find this protuberance bearing a seta closely resembles the endite of the tantulocarid thoracopods (cf. Figs 1-A and 1-C).

A similar structure, though its protrudent feature is not as well developed, is found in the naupliar mandible of other harpacticoid genera, e.g., Longipedia (Gurney, 1930; Nicholls, 1935, see Fig. 1-D; Onbé, 1984), Canuella (Vincx \& Heip, 1979, see Fig. 1-E), Tigriopus (Itô, 1970), Paramphiascella (Rosenfield \& Coull, 1974), cyclopoid genera, e.g., Oithona (Uchima, 1979, see Fig. 1-F), Apocyclops (Valderhaug \& Kewalramai, 1979, Cyclops (Ewers, 1930), and poecilostomatoid genera, e.g., Paranthessius (Briggs, 1977) and Lichomolgus (Costanzo, 1969). Although similar structure is found also in the naupliar mandibles of calanoid copepods, the proximal segment of the protopodite of their naupliar mandibles is usually transformed into a masticatory segment at later stages like the one seen in the copepodids (see Lawson \& Grice, 1970, for Centropages typicus: cf. Figs 1-G and 1-H).

The similarity between the nauplii of certain copepods and cirripeds has repeatedly been pointed out in the literature (Gurney, 1930; Nicholls, 1935; Lang, 
1948; Newman, 1982), and their mandibles are of course the core of the case. Fig. 1-I shows the nauplius I of Balanus amphitrite hawaiiensis Broch as given by Hudinaga \& Kasahara (1942). In this cirriped, the proximal segment of the mandible is slightly protruded inward and bears a seta during the nauplius I but two setae or spines at later naupliar stages. The same or similar structures are found also in other cirripeds, e.g., B. amphitrite denticulata Broch and B. eburneus Gould reported by Costlow \& Bookhout (1957, see Fig. 1-J; 1958), and in B. balanoides (L.) and $B$. balanus (L.) (see Crisp, 1962).

Although the systematic position of the enigmatic crustacean larvae called nauplius $y$ (Hansen, 1899) and their later developmental stage, cypris y, has long been discussed especially in relation with cirripeds and ascothoracids (Bresciani, 1965; T.A. Schram, 1970a, 1972; Hessler, 1982; Grygier, 1983; see also Itô \& Ohtsuka, 1984, and Ito, 1984), they have recently been recognized as a distinct taxon equivalent to Cirripedia and Ascothoracida within the Maxillopoda (Grygier, 1984b). According to T.A. Schram (1970b, 1972), the mandible of his nauplius $y$ has a short seta on the inner edge of the proximal segment of the protopodite (Fig. 1-L). This structure is reminiscent of the one found in the naupliar mandible of copepods and cirripeds. Here, I would like to emphasize that in nauplius $y$ the mandible is clearly patterned after the antenna (cf. Figs $1-\mathrm{K}$ and $1-\mathrm{L}$ ); this nature will be discussed further in a later section but at this point it will suffice to say that two forms of nauplius $y$ without endite on their postantennular appendages are known in Japan, in addition to a usual form with endite (Itô, unpublished).

In short, the most obvious difference between the maxillopodan naupliar mandible and the tantulocarid thoracopod would be that in the latter the endite arises from the proximal extreme of the protopodite which is not two-segmented, whilst in the former the endite bearing a seta which is considered as an equivalent of the tantulocarid endite by me is placed on the proximal segment of the two-segmented protopodite. As a matter of fact, there might be a possibility that Boxshall \& Lincoln (1983) had overlooked the presence of a short proximal protopodal segment that bears the endite. However, Dr. G.A. Boxshall has kindly re-examined the material of $D$. aselloticola upon my request and confirmed their previous observation. He has informed me further that "(the endite) may as such represent the endite of a previously distinct segment that is now completely incorporated into the protopod" (pers. comm.). The reason why tantulocarid endite does not arise from a proximal segment on the protopodite is out of question because there are maxillopodan nauplii with their much reduced proximal protopodal segment being protruded inwards just like tantulocarid endite. The feature found in the nauplii at the later stages of development in Canthocamptus mirabilis is the case in point. In addition, there are also some cirriped nauplii whose proximal segment of the mandibular protopodite is not clearly delimited, rather, it is only represented by a particular form and armature that occur on the inner edge of the protopodite (see Fig. 1-J). Hence, I think there is little difficulty in calling a particular seta-bearing inner portion of the proximal segment of two-segmented protopodite (sympodite) 
of the naupliar mandible of maxillopodans homologous to the endite of the tantulocarid thoracopods. However, question can be raised regarding to the validity of the comparison that was made above between the thoracopods of tantulocarids and the non-thoracic appendages (mandible) of maxillopodans. Before clearing this point, similarity in the general structure between the tantulocarid thoracopods and the postantennular appendages of maxillopodan nauplii must be elucidated as the basis for further discussion.

\section{1-3. General similarity.}

The endopodites of thoracopods $2-5$ of juvenile Deoterthron aselloticola show no structural difference. They are consisted of a peculiar segment which extends somewhat inwards, bears medially (ventrally) two juxtaposed setae, and appears masticatory in function. No maxillopodan adults or juveniles have such endopodites on the thoracic appendages, but nauplii of certain maxillopodans have their appendages with endopodite similar to those found in the tantulocarid thoracopods. The mandibular endopodite of the nauplius I of Canthocamptus mirabilis (Fig. 1-B) consists of two elements: a strong proximal segment with masticatory inner edge and a small ventral outgrowth. The proximal segment is greatly extended inward and armed with two comb-like apical spines and a subterminal seta; the ventral outgrowth is formed near the outer (ventral) base of the proximal segment and bears a few juxtaposed setae. There is no doubt that these two elements of Canthocamptus are homologous to the two well-defined endopodal segments found in other 'primitive' harpacticoids such as Longipedia (Fig. 1-D) and Canuella (Fig. 1-E). Moreover, the proximal segment of the latter genera also exhibits a trend to form a masticatory armature even though it is not as prominent as in C. mirabilis. The mandibular endopodite of Oithona brevicornis nauplii (Fig. 1-F) is simpler than those of the harpacticoids mentioned above: The proximal segment is clearly extended inward and armed with two inner spines which are not basally delimited; the distal segment is tipped with two setae. If this distal segment were reduced and represented by the remaining two juxtaposed setae, the modified endopodite would closely approach the one found in the tantulocarids. The mandibular endopodites of cirriped nauplii can also be explained in the same plan as described above, though their segmentation is not as clear (Fig. 1-I, J). On the other hand, the endopodite of the mandible of nauplius y (Fig. 1-L) consists of two segments, the first shows an underdeveloped masticatory structure, armed with a spine and a seta and the second bears two apical setae. While the armature is like that of $O$. brevicornis its second segment is distinctly shorter. This shorter distal segment with two apical setae approaches closer to the tantulocarid feature where the distal 'segment' is represented by two juxtaposed setae. In addition, I would like to emphasize here, as in the case of the endite, that there is no structural difference between the mandibular endopodite and the antennal endopodite of nauplius y (see Fig. 1-K, L).

Based on the above discussion, it is apparent that the peculiar endopodite of the tantulocarid thoracopods, which appears masticatory, is more in line with the 
first mandibular endopodal segment (masticatory or underdeveloped masticatory) of some maxillopodan nauplii than with the thoracic appendages of maxillopodan adults or juveniles. If this assumption is accepted, then, we can assume further that the two juxtaposed setae on the endopodite of tantulocarid thoracopods represent a reduced feature of a setiferous second segment which is equivalent to the setiferous second endopodal segment found in the mandible of these maxillopodan nauplii.

The exopodite of the thoracopods 1-5 of Deoterthron aselloticola is represented by a short, rudimentary segment bearing four setae which are not clearly defined at base (Fig. A-1). This feature is quite different from a typical maxillopodan thoracopods of either adult or juvenile. Nevertheless, an exopodite possessing four setae is found in the naupliar mandible of certain copepods that were noted above. For instance, Canthocamptus mirabilis has four setae on its two-segmented exopodite (Fig. 1-B), and Oithona brevicornis has four setae on the four-segmented exopodite (Fig. 1-F). Similarly, Centropages typicus has five to six setae on its mandibular exopodite which consists of one to four segments according with stage (Fig. 1-G, $\mathrm{H}$ ), Longipedia coronata has six setae on its four-segmented exopodite (Fig. 1-D), and Canuella perplexa has five or six setae on its four-segmented exopodite (Fig. 1-E). Longipedia and Canuella are generally regarded as primitive members of harpacticoids (Lang, 1948; Por, 1984), therefore, it is likely that their four-segmented flagelliform exopodites also represent a primitive state. If this is the case, then, the exopodite of less than four segments must represents a derived state, at least for harpacticoid nauplii. It is notewcrthy that Boxshall et al. (1984) considered that the ancestral (adult) copepod bore a mandible with five or six segments in the exopodite. On the other hand, the mandibles of cirriped nauplii mentioned above (Fig. 1-I, J) have four to six setae on their exopodites which consist of at least four segments, reminding one of the counterpart found in the copepods, especially the species of Longipedia. The Atlantic forms of nauplius y reported by T.A. Schram (1970b, 1972) have five setae on the mandibular exopodite which is similar to the antennal exopodite and consists of three or four distinct segments with one or two questionable 'segments' (Fig. 1-L. See also Bresciani, 1965). These examples strongly suggest that the mandibular exopodite of maxillopodan nauplii is represented by a multisegmented flagelliform ramus, basically consisting of at least four segments with each of them bearing a lateral seta except for the terminal segment which may have two setae. If the segments of a four-segmented exopodite bearing four setae (one on each segment as in Oithona brevicornis: see Fig. 1-F) were reduced, it would assume very likely a condition that is typical of the tantulocarid thoracopod. There are many known examples that certain setae represent the remnants of their original segments when they were not fused with each other (Lang, 1948; see also Itô, 1982). Although the original number of exopodal segments of the tantulocarid thoracopod is yet to be determined, it would not be illogical to assume that there is a basic structural similarity between the exopodite of tantulocarid thoracopod and that of the naupliar mandible of maxillopodans. 
As repeatedly pointed out above, a close resemblance is found between the mandible and the antenna of nauplius y. It can be said that there is no difference in their basic structure. Although not so obvious as the case in nauplius y, some similarity between the mandible and antenna can be found also in other maxillopodan nauplii (see Williamson, 1982, p. 70). In most cases, with the exception of later naupliar stages of some calanoids, the antenna of the feeding maxillopodan nauplius has a well-developed masticatory edge on the proximal part of the protopodite (see Fig. 1-I), whilst their mandible is devoid of such structure, instead, it has a simple enditic process(es). The most prominent difference between them is in the presence or absence of this masticatory edge. If this difference in the proximal part of the protopodite is disregarded, the essential difference between the naupliar mandible and antenna of maxillopodans would be no longer present. The only other difference, that is not essential, is the number of exopodal segments; the antennal exopodite usually has more segments than the mandibular exopodite. For the convenience of further discussions, the maxillopodan naupliar antenna and mandible are separated into three main types based upon the structure of their protopodites (or sympodites) (see Fig. 2). The one (Fig. 2-A) characterized by the possession of a sclerotized masticatory edge or similar masticatory armature consisting of a large and spiniform, unarticulated, process with or without spines and setae on its proximal segment (or proximal portion, if it is not clearly separated
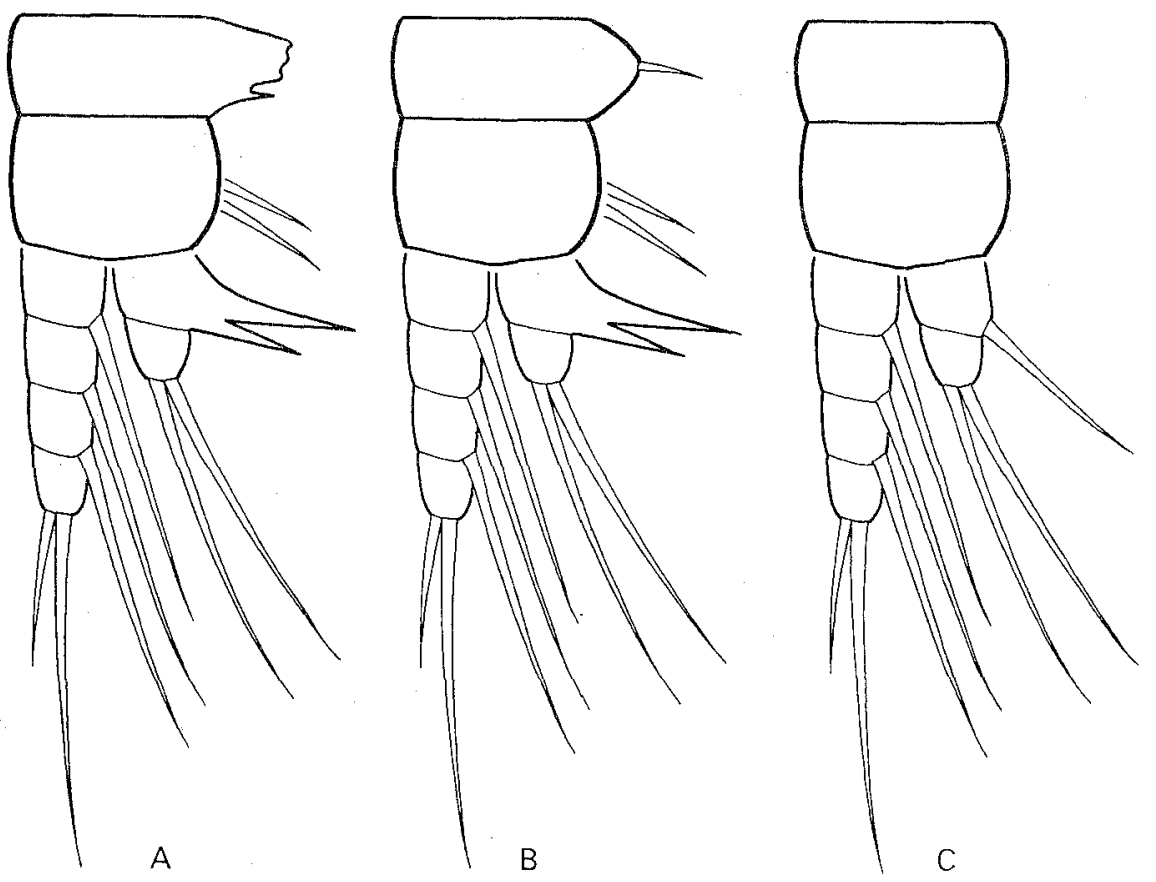

Fig. 2. Three models of naupliar postantennular appendages of maxillopodans, with respect to the armature of the proximal segment of sympodite. A. Mandible-type appendage with masticatory sympodite; B. Mandible-type appendage with submasticatory sympodite; $\mathrm{C}$. Appendage with non-masticatory sympodite. 
into two segments) is called 'masticatory' sympodite; the one (Fig. 2-B) characterized by the possession of a simple endite with a small apical seta (or spine) arising from a well-definable base is called 'submasticatory' sympodite; and the one (Fig. 2-C) without any trace of endite is called 'non-masticatory' sympodite. Two examples of masticatory sympodite are seen in Fig. 1: the antenna of Balanus nauplius (Fig. 1-I) and the mandible at a later naupliar stage of Centropages (Fig. 1-H). Both antenna and mandible of nauplius y illustrated in Fig. 1 are of submasticatory sympodite, and naupliar antenna and mandible of usual ascothoracids (Wagin, 1947; Brattström, 1948) are of non-masticatory sympodite, though both antenna and mandible of Baccalaureus japonicus Broch illustrated by Yoshii (1931) are of masticatory sympodites. Both antenna and mandible of rhizocephalans are of nonmasticatory sympodite (or protopodite) (see Delage, 1884). Incidentally, the exopodite and endopodite of the model appendages labeled as A and B in Fig. 2 are based upon the antenna and mandible of nauplius $y$, and these model appendages are formed to consist of the following three major elements: a multisegmented flagelliform exopodite, an endopodite of very few (two in the models) segments of which the proximalmost is inclined to form a masticatory armature, and a masticatory or submasticatory sympodite (or protopodite with indication of two composit segments). Aside from the number of segments on the exopodite and some minor details of both rami, appendages like these models actually exist and they are typically represented by naupliar mandibles. Such an appendage is accordingly called a 'mandible-type' appendage.

In the following discussion the naupliar 'antenna and mandible' will simply be called 'postantennular appendages', for naupliar (or metanaupliar, to be precise) postmandibular appendages, if present, are usually rudimentary and not functional even in the cases of calanoids that have unusually well-developed postmandibular appendages at later naupliar stages. The similarity in the general structure of naupliar postantennular appendages is not unique to maxillopodans (see Sanders, 1963, p. 70, Hessler \& Newman, 1973, p. 451, Hessler, 1982, p. 158), but to equate them with the thoracopods of juvenile tantulocarids would necessitate a consideration on the phylogenetic origin of the tantulocarid thoracopod.

\section{Origin of Tantulocarid Thoracopods}

In the previous section, I did not explain why thoracopods of one group of the Crustacea can be equated with the naupliar postantennular appendages of another group when these appendages are non-thoracic at juvenile and adult stages. However, my assumption is supported by the fact that there is a series of mandible-type appendages present in some extinct crustaceans like phosphatocopine ostracodes, such as Vestrogothia spinata Müller, from the Upper Cambrian of Sweden (Müller, 1979; see also McKenzie et al., 1983). Although it is still a matter of dispute whether these extinct crustaceans are true ostracodes (see F.R. Schram, 1982, p. 111), which are regarded as potentially attributable to the Maxillopoda (Newman et al., 
1969; Hessler \& Newman, 1975; Grygier, 1983), the point I am trying to make here is that in some primitive crustaceans there is a scries of appendages that are devoid of essential morphological distinction between the cephalic and thoracic, or the oral and postoral. It should also be emphasized that these uniform appendages resemble closely the model appendages that were developed above for the postantennular appendages of maxillopodan nauplii (see also Grygier, 1983, p. 83, for the similarity of appendages between phosphatocopine ostracodes and maxillopodan nauplii). The basic feature of the third appendage of a phosphatocopine ostracod, such as Bradoriidarum sp. (Müller, 1979), is as follows: The protopodite is armed with spinules and forms a well-developed gnathic edge; the endopodite consists of two segments, with the protruded proximal segment bearing spine (and/or setae) to assume an underdeveloped masticatory edge and the small distal segment carrying two apical setae; the exopodite is of multisegmented flagelliform and armed with a few setae on the terminal segment apically and with a seta on each of the other segments unilaterally. The major difference between this ostracod appendage and the proposed basic plan of the postantennular appendages of maxillopodan nauplii lies in the number of segments of the exopodite (18 for the former's), but this difference becomes insignificant if more posterior and/or underdeveloped appendages of ostracodes are taken into consideration. The protopodite of this appendage displays some differences, it has a well-developed gnathic edge bearing many spines and appears like the protopodite of general trunk appendages of cephalocaridans and trilobites. Apart from these differences, the cases of phosphatocopine ostracodes with a series of practically uniform and almost mandible-type appendages clearly indicate that in the ancestral Crustacea (either Maxillopoda or pre-Maxillopoda) the mandible-type appendages were not necessarily restricted to the antenna or mandible, but could have occurred in further posterior appendages (first four or five pairs of the appendages are actually of the mandible-type for these fossil ostracodes).

As a matter of fact, the similarity between postantennular appendages in ancestral curstaceans has already been speculated by some workers, notably Sanders (1963) and Hessler \& Newman (1975). Hessler \& Newman proposed a hypothetical ancestral crustacean with mixopodium-type appendages on cephalon as well as trunk somites (to be precise, they proposed two models which differed from each other in the structure of the carapace). In addition, the antenna of this ancestral crustacean is "essentially postoral, much as in the nauplius, and shows a high degree of serial homology with trunk limbs." They noted further that "the postantennal head limbs and trunk segments all bear serially very similar limbs" (quotations from Cisne, 1982, p. 69). Although these characteristics were intended for the adult ancestral crustacean, such a level of organization is exhibited only by the Cephalocarida among the extant crustaceans (see Sanders, 1955, 1957, 1963). Although adult remipedians have a very long series of similar trunk appendages, all of their postantennular appendages on the head are highly differentiated (Yager, 1981) and resemble the much differentiated head appendages of the Copepoda, 
especially the Calanoida (Itô, 1983). In connection with the reality of Hessler \& Newman's hypothetical urcrustacean, Cisne (1982) suggests that high similarity between the antenna and postantennal limbs would be a characteristic of the ancestral crustacean's nauplius larva. Many examples are known to support that "the larva of the descendant represents the larval and not the adult of the ancestor" (de Beer, 1951). Hessler \& Newman's hypothetical urcrustacean might be more applicable to larval or juvenile stages than to adult of ancestral crustaceans. At any rate, Hessler \& Newman's hypothesis seems to support my contention that it is not illogical to compare between the naupliar postantennular appendages of one group that are non-thoracic at juvenile and adult stages with the juvenile thoracic appendages of another group.

As already mentioned, systematic position and phylogeny of the Tantulocarida have been discussed by some workers mainly in relation to maxillopodans such as the Ascothoracida and Rhizocephala. In this connection, Boxshall \& Lincoln (1983) were first to point out the difference between the tantulocarid thoracopods with endite and maxillopodan thoracic appendages in terms of the endite. They suggested that "the endite is derived from the cephalocaridan type of protopodal endite attributed to the urcrustacean by Hessler \& Newman (1975) and which is thus regarded as plesiomorphic to the Crustacea." Their assumption of the endite being originated from the cephalocaridan-type protopodite might not be impossible and, I believe, even taking it further back to a trilobite level of origin is also feasible; nevertheless, especially in the case of the Tantulocarida, such backward tracking to very remote ancestors does make it obscure what tantulocarid thoracopods actually imply as an evidence of evolutional novelty. The origin of tantulocarid thoracopods in terms of its peculiar endite should be carefully examined in relation to maxillopodans and not cephalocaridans, because the protopodite of a typical cephalocaridan limb does not have a simple and proximally placed endite with one apical seta, instead, there is a complex gnathic structure along its entire inner edge, which is separated into some lobules with many spines and/or setae. In my opinion, before pursuing such a direct back tracking of tantulocarid endite to cephalocaridan-type protopodite, one must examine the reason why the proximalmost enditic lobule remained unchanged while a complete degeneration occurs in all of the other enditic lobules. On the other hand, despite the fact that mandible-type appendages, as well as appendages supposed to have been derived from them, are common to the antennae and mandibles of maxillopodans (here it includes both ascothoracids and mystacocarids, though their appendages differ to some extent from those of other maxillopodan nauplii) and some non-maxillopodan crustaceans (especially, the larval stages of branchiopods; see Sanders, 1963, Fig. 28), it is almost only in the Maxillopoda that we find the kind of appendages as depicted in Fig. 2-B with submasticatory sympodite. Hence, I find there is a certain significant difference between the cephalocaridan protopodites and tantulocaridan-maxillopodan protopodites with respect to the endite. It is assumed that from this submasticatory sympodite (Fig. 2-B) another form of submasticatory sympodite (Fig. 3) was developed through 

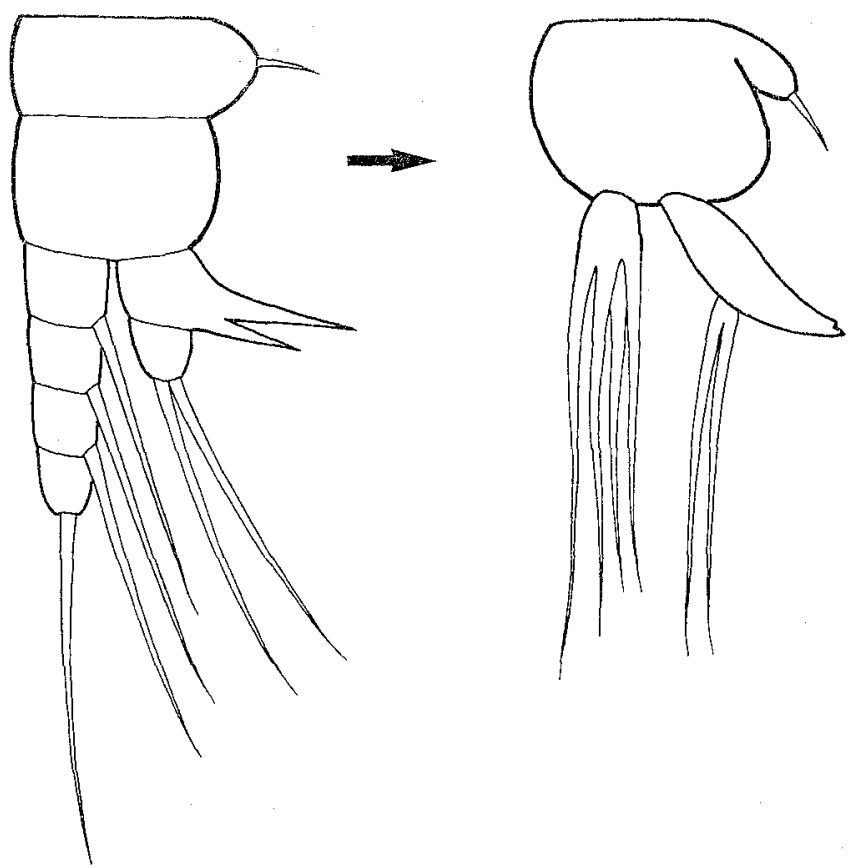

Fig. 3. A possible derivation of the tantulocarid thoracopod (right) from a mandible-type appendage with submasticatory sympodite (left).

losing setae on the distal segment, because these setae on the distal segment may degenerate independent of the transformation of the endite on the proximal segment.

Tantulocarid thoracopods bear close resemblance with the postantennular appendages of maxillopodan nauplii, especially with the type of submasticatory sympodite (Fig. 3). If this view is accepted, then, the absence of intercoxal sclerite between each pair of thoracopods of tantulocarids (Boxshall \& Lincoln, 1983, p. 12) would also be resolved because naupliar postantennular appendages of maxillopodans are devoid of intercoxal sclerite. I speculate that they were formed from a common basic plan and, in the case of tantulocarid thoracopods, deviation from this common basic plan has taken place by simplification and specialization through their parasitic life.

The submasticatory sympodite in a maxillopodan nauplius appears either as an underdeveloped structure which becomes a masticatory form at later developmental stages or as an underdeveloped structure that ceases further differentiation at an early developmental stage. The latter case may be regarded as a degenerative feature. Similarly, even though some different cases might be equally possible, the protopodite of the extant tantulocarids may be postulated as the one showing a degenerative feature of their immediate ancestor with submasticatory sympodite on each of the corresponding thoracopods. The thoracopodal sympodite of this 'immediate ancestor' may possess an underdeveloped structure of the still older ancestors. In this case, there is a possibility that this underdeveloped feature was a 
characteristic of thoracic appendages at certain larval stages of a tantulocarid ancestor which had more pedigerous somites at later stages than the extant tantulocarids. Furthermore, I speculate the thoracic appendages of this tantulocarid ancestor at these larval stages were of a mandible-type and, at postlarval (juvenile and adult) stages, they were structurally distinct from the larval ones.

\section{Concluding Remarks}

Although I have explained the peculiar structure of tantulocarid thoracopods by relating it with a generalized type of naupliar postantennular appendages of some maxillopodans, my explanation raises several problems for the phylogenetic studies of maxillopodans (in broad sense) and tantulocarids. For example, posterior four pairs of branchiuran appendages (legs), which somewhat differ from the thoracic appendages of other maxillopodans, will have to be re-examined with regard to mandible-type appendages. Branchiuran legs are devoid of intercoxal sclerite, and those of certain larval stages (e.g., leg 1 of Argulus japonicus Thiele at the fourth larval stage: see Tokioka, 1936) are similar to a mandible-type appendage with submasticatory sympodite rather than to thoracic appendages of copepods, cirriped cyprids, ascothoracids, or cypris y. The identity of a single seta (or spine) which attaches to the inner edge of the coxa of certain copepod legs (e.g., legs 1-4 of Longipedia: see Itô, 1980; such examples abound among cyclopoids, see any taxonomic papers) would also be questionable, for ascothoracids have as many as 12 setae on the coxa of legs (see Grygier, 1984a). In fact, this setose coxa in ascothoracid legs has made me wonder whether the single coxal seta on copepod legs is indeed a homologue of the tantulocarid thoracopodal endite or an equivalent of the enditic seta of submasticatory sympodite of naupliar postantennular appendages. Even if the coxal inner seta of copepod legs could be related to setae on the gnathic edge of the cephalocaridan-type protopodite of trunk limbs, one would have to assume that several unknown steps and events must have occurred before reaching the state of possessing a single seta.

On the other hand, it is possible that the ancestor of tantulocarids might have more pedigerous somites at later developmental stages than the extant tantulocarids. In addition, this ancestral crustacean might have as many head appendages as suggested by Grygier (1983) for his urmaxillopodan or by Tiemann (1984) for a model of Copepodoidea. This hypothetical animal can be a reality because there exist crustaccans with copepod-like head and numerous trunk somites, such as Speleonectes lucayensis Yager, 1981 (Some undescribed species and genera of the Remipedia also exist: F.R. Schram, pers. comm.). Within this context and in contrast to Newman's view (Newman, 1983, p. 108), I am expecting that when larval or postlarval development of remipedians is made known, the origin of most maxillopodan taxa as well as tantulocarids will become more clearly explainable. The presence of a pair of bifurcate processes on remipedian head (Yager, 1981), which is one of the most serious problems in relating remipedians with maxillopodans, will perhaps 
become insignificant (Itô, in press).

Tantulocarid juveniles and adults show strong trends of degeneration in various aspects. The lack of definable appendages on the head is the case in point. It seems that the short exopodal segment and rudimentary second endopodal segment of their thoracopods are resulted as a degeneration from their ancestral features. Such trend of degeneration and simplification could have occurred through neotenic evolution that is so commonly found in many groups of maxillopodans and related taxa. However, this commonness should not be dismissed as a mere convergence, because degenerative or simplified creatures might exhibit some ancestral structural elements that persisted in them. To find these essential common elements between seemingly different structures, or, for that matter, the essential differences between seemingly similar structures, is of great importance in phylogenetic consideration.

\section{Acknowledgments}

I would like to express my sincere thanks to Dr. G.R. Boxshall, the British Museum, and Professor E. Harada, Kyoto University, who critically read earlier drafts of the manuscript and commented on them. Special thanks are due to Professor J.-S. Ho, the University of California, who carefully reviewed the manuscript and offered many helpful suggestions. While indebted to them, responsibility for crrors or other oversights falls on me. This work is supported in part by the Grant-inAid for Scientific Research, No. 58540482, from the Ministry of Education, Science and Culture, Japan.

\section{References}

Becker, K.-H. 1975. Basipodella harpacticola n. gen., n. sp. (Grustacea, Copepoda). Helgol. wiss. Meeresunters., 27: 96-100.

Beer, G.R., de. 1951. Embryos and ancestors. Revised edition. xii +159 , pp. The Clarendon Press, Oxford.

Boxshall, G.A. 1983. A comparative functional analysis of the major maxillopodan groups. In: R.R. Schram ed., Grustacean phylogeny, pp. 121-143. A.A. Balkema, Rotterdam.

—_ \& R.J. Lincoln. 1983. Tantulocarida, a new class of Crustacea ectoparasitic on other crustaceans. J. crust. Biol., 3: 1-16.

— F.D. Ferrari \& H. Tiemann. 1984. The ancestral copepod: Towards a consensus of opinion at the first international conference on Copepoda. Crustaceana Suppl., 7: 68-84.

Bradford, J.M., \& G.C. Hewitt. 1980. A new maxillopodan crustacean, parasitic on a myodocopid ostracod. Crustaceana, 38:67-72.

Brattström, H. 1948. Undersökningar över Oresund. XXXIII. On the larval development of the ascothoracid Ulophysema öresundense Brattström. Studies on Ulophysema öresundense. 2. Kungl. Fysiogr. Sällskap. Handl., N.F., 59 (5) : 1-70.

Bresciani, J. 1965. Nauplius " $y$ " Hansen. Its distribution and relationship with a new cypris larva. Vidensk. Medd. fra Dansk Naturh. Foren., 128: 245-258.

Briggs, R.P. 1977. Larval stages of Paranthessius anemoniae Claus (Copepoda, Cyclopoida), an associate of the snakelocks anemone Anemonia sulcata (Pennant). Crustaceana, 33: 249-258.

Gisne, J.L. 1982. Origin of the Grustacea. In: L. Abele, ed., The biology of Crustacea, vol. 1, pp. 65-92. Academic Press, New York.

Costanzo, G. 1969. Stadi naupliari e primo copepodite di Lichomolgus canui G.O. Sars (Copepoda, Cyclopoida) del Lago di Faro (Messina), allevata sperimentalmente. Boll. Zool., 36: 143-153.

Costlow, Jr., J.D., \& C.G. Bookhout. 1957. Larval development of Balanus eburneus in the laboratory. Biol. Bull., 112 : 313-324. 
___ \& 1958. Larval development of Balonus amphitrite var. denticulata Broch reard in the laboratory. Ibid., 114: 284-295.

Crisp, D.J. 1962. The planktonic stages of the Cirripedia Balanus balanoides (L.) and Balanus balanus (L.) from north temperate waters. Crustaceana, 3: 207-221.

Delage, Y. 1884. Evolution de la Sacculine. Arch. Zool. cxp. gen., 2 (2): 417-736, 9 pls.

Delamare Deboutteville, Cl. 1953. Recherches sur l'ecologie et la repartition du Mystacocaride Derocheilocaris remanei Delamare et Chappuis, en Mediterranee. Vie Milieu, 4: 321-380.

Ewers, L.A. 1930. The larval development of freshwater Copepoda. 43 pp. The Ohio State University Press, Columbus.

Grygier, J.J. 1983. Ascothoracida and the unity of Maxillopoda. In: F.R. Schram, ed., Crustacean phylogeny. pp. 73-104. Balkema Publishers, Rotterdan.

- 1984a. Ascothoracida (Crustacea: Maxillopoda) parasitic on Chrysogorgia (Gorgonacea) in the Pacific and western Atlantic. Bull. mar. Sci., 34: 141-169.

-1984b. Comparative morphology and ontogeny of the Ascothoracida, a step toward a phylogeny of the Maxillopoda. xxi $+417 \mathrm{pp} . \mathrm{Ph}$. D. Thesis. University of California, San Diego.

Gurney, R. 1930. The larval stages of the copepod Longipedia. J. mar. biol. Ass. U. K., N.S., 16: 461-474.

Hansen, H.J. 1899. Die Cladoceren und Cirripedien der Plankton-Expedition. Ergebnisse der Plankton-Expedition der Humboldt-Stiftung, 2 (G.d) : 1-58, pls. I-IV.

Hessler, R.R. 1982. Evolution within the Crustacea. In: L. Abele, ed., The biology of Grustacea, vol. 1, pp. 150-185. Academic Press, New York.

— $437-457$.

Hudinaga, M., \& H. Kasahara. 1942. On the rearing and metamorphosis of Balanus amphitrite hazeaiiensis Broch. Zool. Mag., Tokyo, 54: 108-118.

Itô, T. 1970. The biology of a harpacticoid copepod Tigriopus japonicus Mori. J. Fac. Sci. Hokkaido Univ., Ser. VI, Zool., 17: 474-500, pls. VII-VIII.

- 1980 . Two species of the genus Longipedia Claus from Japan, with reference to the taxopomic status of $L$. weberi previously reported from Amakusa, southern Japan (Copepoda: Harpacticoida). J. nat. Hist., 14: 17--32.

- 1982. The origin of 'biramous' copepod legs. Ibid., 16: 715-726.

-1983. The origin of Copepoda (Crustacea). Zool. Mag., Tokyo, 92: 664. (In Japanese) - 1984. Another cypris y from the North Pacific, with reference to the bending behavior exhibited by a cypris y specimen of the formerly described type (Crustacea: Maxillopoda). Publ. Seto mar. biol. Lab., 29: 367-374.

- (In press). Contributions to the knowledge of cypris y (Crustacea: Maxillopoda), with reference to a new genus and three new species from Japan. Spec. Publ. Mukaishima mar. biol. Stn, 1985.

- , \& S. Ohtsuka. 1984. Cypris y from the North Pacific (Crustacea: Maxillopoda). Publ. Seto mar. biol. Lab., 29: 179-186.

- \& T. Takashio. 1980. The larval development of Canthocamptus mirabilis Š Šrba (Copepoda, Harpacticoida), with reference to the bionomics. J. Fac. Sci. Hokkaido Univ., Ser. VI, Zool., 22: 279-300.

Lang, K. 1948. Monographie der Harpacticiden. 1682 pp. Hakan Ohlssons Boktrykeri, Lund.

-. 1965. Copepoda Harpacticoidea from the Californian Pacific coast. Kungl. Svenska Vetenskapsakad. Handl., 10(2): 1-560, pls. 1-6.

Lawson, T.J., \& G.D. Grice. 1970. The developmental stages of Centropages typicus Kr $\phi$ yer (Copepoda, Calanoida). Crustaceana, 18: 187-208.

Lincoln, R.J., \& G.A. Boxshall. 1983. A new species of Deoterthron (Crustacea: Tantulocarida) ectoparasitic on a deep-sea asellote from New Zealand. J. nat. Hist., 17: 881-889.

McKenzie, K.G., K.J. Muiller \& M.N. Gramm. 1983. Phylogeny of Ostracoda. In: F.R. Schram, ed., Crustacean phylogeny, pp. 29-46. Balkema Publishers, Rotterdam.

Müler, K.J. 1979. Phosphatocopine ostracodes with perserved appendages from the Upper Cambrian of Sweden. Lethaia, 12: 1-27. 
Newman, W.A. 1982. Evolution within the Crustacea. Pt. 3: Cirripedia. In: L. Abele, ed., The biology of Crustacea, vol. 1, pp. 197-211. Academic Press, New York.

Newman, W.A. 1983. Origin of the Maxillopoda; Urmalacostracan ontogeny and progenesis. In: F.R. Schram, ed., Grustacean phylogeny, pp. 105-119. Balkema Publishers, Rotterdam.

- V.A. Zullo \& T.H. Withers. 1969. Cirripedia. In: R.C. Moore, ed., Treatise on invertebrate palcontology, Arthropoda 4 (1): R206-R295.

Nicholls, A.G. 1935. The larval stages of Longipedia coronata Claus, L. scotti G.O. Sars, and L. minor T. and A. Scott, with a description of the male of $L$. scotti. J. mar. biol. Ass. U. K., N.S., 20: 29-45.

Onbé, T. 1984. The developmental stages of Longipedia americana (Copepoda: Harpacticoida) reared in the laboratory. J. crust. Biol., 4: 615-631.

Por, F.D. 1984. Canuellidae Lang (Harpacticoida, Polyarthra) and the ancestry of the Copepoda. Crustaceana Suppl., 7:1-24.

Rosenfield, D.C. 1967. The external morphology of the developmental stages of some diosaccid harpacticoid copepods (Crustacea) from Massachusetts Bay. vii $+298 \mathrm{pp}$. Ph. D. Thesis. Boston University Graduate School, Boston.

-, \& B.C. Coull. 1974. Adult morphology and larval development of Paramphiascella fultofasciata n. sp. (Copepoda, Harpacticoida). Cah. Biol. Mar., 15: 295-317.

Sanders, H.L. 1955. The Cephalocarida, a new subclass of Crustacea from Long Island Sound. Proc. natn. Acad. Sci., 41:61-66.

- 1957. The Cephalocarida and crustacean phylogeny. Syst. Zool., 6: 112-128.

1963. The Cephalocarida. Functional morphology, larval development, comparative external anatomy. Mem. Connect. Acad. Arts \& Sci., 15: 1-80.

Schram, F.R. 1982. The fossil record and evolution of Crustacea. In: L. Abele, ed., The biology of Crustacea, vol. 1, pp. 93-147. Academic Press, New York.

Schram, T.A. 1970a. Marine biological investigations in the Bahamas. 14. Cypris y, a later developmental stage of nauplius y Hansen. Sarsia, 44: 9-24.

- 1970b. On the enigmatical larva nauplius y type I Hansen. Ibid., 45: 53-68.

- 1972. Further records of nauplius y type IV Hansen from Scandinavian waters. Ibid., $50: 1-24$.

Tiemann, H. 1984. Is the taxon Harpacticoida a monophyletic one? Crustaceana Suppl., 7: 4759.

Tokioka, T. 1936. Larval development and metamorphosis of Argulus japonicus. Mem. College Sci. Kyoto Imp. Univ., Ser. B, 12: 93-114.

Uchima, M. 1979. Morphological observation of developmental stages in Oithona brevicornis (Copepoda, Cyclopoida). Bull. Plankt. Soc. Japan, 26: 59-76.

Valderhaug, V.A., \& H.G. Kewalramani. 1979. Larval development of Apocyclops dengizicus Lepeshkin (Copepoda). Crustaceana, 36:1-8.

Vincx, M., \& G. Heip. 1979. Larval development and biology of Canuella perplexa T. and A. Scott, 1893 (Copepoda, Harpacticoida). Cah. Biol. Mar., 20: 281-299.

Wagin, W.L. 1947. Ascothorax ophioctenis and the position of Ascothoracida Wagin in the system of the Entomostraca. Acta zool., 27: 155-267.

Williamson, D.I. 1982. Larval morphology and diversity. In: L. Abele, ec., The biology of Crustacea, vol. 2, pp. 43-110. Academic Press, New York.

Yager, J. 1981. Remipedia, a new class of Crustacea from a marine cave in the Bahamas. J. crust. Biol., 1 : 328-333.

Yoshii, H. 1931. Note on the organization of Baccalaureus japonicus. Annot. zool. Japon., 13: 169187. 